\title{
SOEP
}

SOEPpapers

on Multidisciplinary Panel Data Research

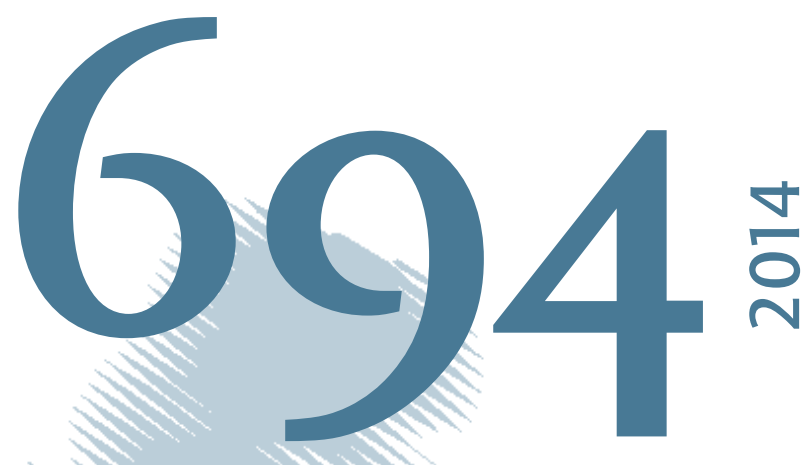

\section{Intergenerational transmission of unemployment - evidence for German sons}




\section{SOEPpapers on Multidisciplinary Panel Data Research}

at DIW Berlin

This series presents research findings based either directly on data from the German SocioEconomic Panel Study (SOEP) or using SOEP data as part of an internationally comparable data set (e.g. CNEF, ECHP, LIS, LWS, CHER/PACO). SOEP is a truly multidisciplinary household panel study covering a wide range of social and behavioral sciences: economics, sociology, psychology, survey methodology, econometrics and applied statistics, educational science, political science, public health, behavioral genetics, demography, geography, and sport science.

The decision to publish a submission in SOEPpapers is made by a board of editors chosen by the DIW Berlin to represent the wide range of disciplines covered by SOEP. There is no external referee process and papers are either accepted or rejected without revision. Papers appear in this series as works in progress and may also appear elsewhere. They often represent preliminary studies and are circulated to encourage discussion. Citation of such a paper should account for its provisional character. A revised version may be requested from the author directly.

Any opinions expressed in this series are those of the author(s) and not those of DIW Berlin. Research disseminated by DIW Berlin may include views on public policy issues, but the institute itself takes no institutional policy positions.

The SOEPpapers are available at

http://www.diw.de/soeppapers

\section{Editors:}

Jürgen Schupp (Sociology)

Gert G. Wagner (Social Sciences, Vice Dean DIW Graduate Center)

Conchita D'Ambrosio (Public Economics)

Denis Gerstorf (Psychology, DIW Research Director)

Elke Holst (Gender Studies, DIW Research Director)

Frauke Kreuter (Survey Methodology, DIW Research Professor)

Martin Kroh (Political Science and Survey Methodology)

Frieder R. Lang (Psychology, DIW Research Professor)

Henning Lohmann (Sociology, DIW Research Professor)

Jörg-Peter Schräpler (Survey Methodology, DIW Research Professor)

Thomas Siedler (Empirical Economics)

C. Katharina Spieß (Empirical Economics and Educational Science)

ISSN: 1864-6689 (online)

German Socio-Economic Panel Study (SOEP)

DIW Berlin

Mohrenstrasse 58

10117 Berlin, Germany

Contact: Uta Rahmann | soeppapers@diw.de 


\title{
Intergenerational transmission of unemployment - evidence for German sons
}

\author{
Miriam Mäder \\ Steffen Müller \\ Regina T. Riphahn \\ Caroline Schwientek \\ University of Erlangen-Nuremberg
}

24 September, 2014

This paper studies the association between the unemployment experience of fathers and their sons. Based on German survey data that cover the last decades we find significant positive correlations. Using instrumental variables estimation and the Gottschalk (1996) method we investigate to what extent fathers' unemployment is causal for offsprings' employment outcomes. In agreement with most of the small international literature we do not find a positive causal effect for intergenerational unemployment transmission. This outcome is robust to alternative data structures and to tests at the intensive and extensive margin of unemployment.

JEL Code: J 62, C 21, C 26

Keywords: $\quad$ youth unemployment, non-employment, intergenerational mobility, causal effect, Gottschalk method

Correspondence to:

Regina T. Riphahn

Univ. of Erlangen-Nuremberg

Lange Gasse 20

90403 Nuremberg, Germany

Phone: +49 - 911 - 5302826

Fax: $\quad+49$ - 911 - 5302178

Email: regina.riphahn@fau.de 


\section{Introduction}

Unemployment of young individuals is one of the most pressing labor market problems of our times. Recently, some of the crisis ridden European economies faced youth unemployment rates well beyond 20 percent which instigate not only poverty and a sense of desperation but also waves of emigration and delays in family formation. The literature shows that the early experience of unemployment can be influential for lifetime labor market opportunities (e.g., Gregg 2001, Schmillen and Umkehrer 2013). However, while most commentators agree on the significance of early unemployment there is surprisingly little discussion and evidence on some of its key determinants especially the family background. In this paper we study the intergenerational transmission of unemployment experience, describe its patterns, and investigate causal relationships.

A number of mechanisms may relate parent and child unemployment. They comprise correlated observable characteristics of parent and child, correlated unobservable characteristics, and true causal effects of parent unemployment on child unemployment. Clearly, observable characteristics such as formal education, choice of industry, occupation, region of residence, or social networks are correlated across generations and may affect employment outcomes. Similarly, it is plausible that unobservables such as ability, motivation, attitudes, beliefs, or personality traits are shared between parents and their children and may affect the risk of experiencing an unemployment spell.

However, causal connections between parent and child unemployment are of particular interest. Such causal mechanisms may generate both positive and negative effects: the experience of parental unemployment may affect household and family tastes and attitudes and reduce the perceived stigma of unemployment. Also, it may reduce child human capital investments as a consequence of reduced household income or unemployment-related stress in the family. These mechanisms suggest a positive correlation between parent and child unemployment. On the other hand it is possible that the additional leisure of an unemployed 
parent benefits the offspring and that the family values human capital more after experiencing a loss of employment. In that case one might as well expect a negative correlation between parent and child unemployment.

The literature on the intergenerational transmission of unemployment has studied the situation for Canada (Corak et al. 2004, Oreopoulos et al. 2008), the U.K. (Johnson and Reed 1996, O'Neill and Sweetman 1998, Macmillan 2010, Gregg et al. 2012), Norway (Bratberg et al. 2008, Ekhaugen 2009), and Sweden (Corak et al. 2004). While almost all studies yield positive intergenerational correlations of unemployment, the evidence on true causal effects of parent on child unemployment is mixed. Only the two studies on Canada appear to support a causal intergenerational effect while all others find insignificant effects.

We add to this inconclusive literature by offering evidence for Germany, a country for which intergenerational transmission of unemployment has not been studied before. Germany is a particularly interesting case because on the one hand it is well known for its low youth unemployment (Riphahn and Zibrowius 2014) and on the other hand it features low intergenerational mobility and high intergenerational correlation of economic outcomes e.g. compared to Scandinavian countries (see, e.g., Couch and Dunn 1997, or Schnitzlein 2014 and studies cited there). This provides a unique setting that has not been studied before. We take advantage of long running panel data from the German Socio-Economic Panel (SOEP) to investigate the correlation and causation patterns between fathers' and sons' unemployment experience.

We are interested in both intergenerational correlation patterns and causal parent-child effects which we identify based on an instrumental variables approach and the Gottschalk (1996) method. The evidence on correlation patterns yields the gross impact of family background and parental unemployment on child unemployment risks. This is of interest in itself and in its heterogeneity across population groups; certainly, the relevance of high intergenerational unemployment correlation (i.e., of low intergenerational mobility) differs if 
correlations are strong in families with low as opposed to high unemployment risk. Such patterns can be evaluated independent of causal analyses that separate family unobservables from the true causal parental unemployment effect. As the two components of intergenerational correlation have different policy implications it is important to clarify their relative importance.

Our analyses yield three key results: first, the unemployment experience of fathers and sons is significantly positively correlated; second, there is no evidence in favor of positive causal intergenerational effects; third, most of the intergenerational unemployment correlation is associated with paternal characteristics such as age and education.

This paper is structured as follows. We first summarize key findings and approaches of the literature on the intergenerational transmission of labor market outcomes and discuss our empirical methods. Then we describe our data. The results section presents findings of least squares regressions, instrumental variables analyses, an application of the Gottschalk (1996) method, and robustness tests. In section 5 we conclude with a summary of our findings.

\section{Literature and empirical approach}

\subsection{Existing evidence on intergenerational transmission of labor market outcomes}

Several empirical studies investigate the relation between the outcomes of parents and their children with a focus on unemployment and welfare receipt. Studies on unemployment transmission look at the relation of father and son outcomes (e.g., O'Neill and Sweetman 1998, Ekhaugen 2009) while studies on welfare receipt in the U.S. typically analyze transmission from mother to daughter (e.g., Antel 1992, Gottschalk 1990, 1996). Gottschalk (1990) shows a strong positive intergenerational correlation in welfare receipt using U.S. data and speculates whether this correlation is a causal effect or explained by family background. Antel (1992) and Gottschalk (1996) report a causal effect of mothers' welfare receipt on daughters' welfare receipt. In a more recent study, Beaulieu et al. (2005) analyze the relation between parents' and children's receipt of social assistance in Canada and report similar results, i.e., a strong positive 
correlation that can be interpreted causally. These studies' results rely on untestable identifying assumptions, e.g., assumptions on the joint distribution of unobservables or the validity of exclusion restrictions. A new paper using Swedish data and comparing siblings (Edmark and Hanspers 2012) finds no causal relation between parental welfare use and welfare use of the next generation.

The literature on the transmission of unemployment from father to son yields a more homogenous picture. Studies for the U.K. (Johnson and Reed 1996, O'Neill and Sweetman 1998, Macmillan 2010), Norway (Ekhaugen 2009), Canada, and Sweden (Corak et al. 2004) report a strong positive intergenerational correlation in the incidence of unemployment, but no study finds clear evidence for a causal mechanism. Studies exploiting father's displacement due to mass layoffs or plant closures yield mixed results. Oreopolous et al. (2008) find a higher unemployment risk for children of displaced fathers in Canada. Similarly, Gregg et al. (2012) report a 1.5 percent higher youth unemployment duration for children of fathers who worked in industries with adverse employment shocks during the 1980 recession in the U.K.. If, however, father's job displacement is related to his unobserved characteristics, these estimates might mix the effect of family background with the causal effect of parental unemployment. Using Norwegian data, Bratberg et al. (2008) find no effect of father's displacement on child's later earnings. Taken together, international evidence points at observed and unobserved family background characteristics as predominant drivers of the intergenerational correlation of unemployment. ${ }^{1}$

To the best of our knowledge there exists no single study for Germany systematically exploring the intergenerational transmission of unemployment. Franz et al. (2000) analyze the transition from vocational training to permanent jobs and find a prolonged unemployment duration for children from households where the head of the household is unemployed. Franz 
et al. (2000) do not distinguish empirically between causality and the influence of family background. A recent paper by Pinger (2012) reports a negative causal effect of paternal unemployment on the probability of upper secondary school choice. Pinger (2012) also finds negative effects on child self-confidence and mental health and a more external locus of control for affected children. All in all, there is some evidence on negative effects of parental unemployment for Germany but no systematic study on the intergenerational transmission of unemployment.

\subsection{Model and relevant estimation methods}

A regression of son's unemployment experience in the observation period $(t 1)$ on father's unemployment history in a previous period $(t 0)$ (and a vector of son and father characteristics) yields a measure of the correlation between father's and son's unemployment outcomes. ${ }^{2}$ This is interesting as it shows whether sons of unemployed fathers are more or less likely to become unemployed themselves. The correlation can be interpreted as the causal effect of father's unemployment history if the latter is uncorrelated with the error term in the son's unemployment equation. This is unlikely because the reasons for father's and son's unemployment may have a common component shared by all family members. Family background may include biological factors, ability, or similar tastes and preferences concerning work. Consider the following model:

$$
\begin{aligned}
& u n_{\text {sit } 1}=u n_{f i t 0} \beta+x_{\text {sit } 1}^{\prime} \gamma+\varepsilon_{\text {sit } 1} \\
& u n_{f i t 0}=x_{f i t 0}^{\prime} \delta+\varepsilon_{f i t 0}
\end{aligned}
$$

where $s$ denotes sons, $f$ fathers, $i$ families, $t 0$ and $t 1$ refer to the past and ongoing time periods, and $\beta, \gamma$, and $\delta$ are parameter vectors. Son's unemployment $u n_{\text {sit } 1}$ is affected by the father's

\footnotetext{
2 In our empirical application we will consider the son's age 10-15 to represent period t0, and son's age 1724 to represent period $t 1$.
} 
unemployment history $u n_{\text {fit } 0}$ and a vector of control variables $x$. The error terms are defined as

$$
\varepsilon_{\text {sit } 1}=\alpha_{s i}+\tau_{s i t 1}
$$

and

$$
\varepsilon_{f i t 0}=\alpha_{f i}+\tau_{f i t 0}
$$

$\tau_{\text {sit } 1}$ and $\tau_{\text {fit } 0}$ being white noise errors with zero covariance. If family background is relevant for father's and son's unemployment propensity, then we expect $\operatorname{corr}\left(\alpha_{s i} ; \alpha_{f i}\right)>0$. This correlation generally biases OLS estimates of equation (1) in the sense that $\beta$ is not reflecting the causal effect of paternal unemployment history, only. The biased estimate, instead, mixes the effects of family background and paternal unemployment. The challenge is to determine which part is causal and which reflects the influence of family background. Both effects are interesting but have different policy implications. In previous studies three methods have been used to disentangle family background and true causal effects.

Ekhaugen (2009) compares siblings who have been at different ages at the time of parental unemployment. On the basis of assumptions about the age after which parental unemployment does and does not affect a child's employment outcomes, sibling differences can net out the effect of family background.

Other scholars estimate the system of equations (1) and (2) and either model $\operatorname{cov}\left(\varepsilon_{s i t 1} ; \varepsilon_{f i t 0}\right)$ within a bivariate probit framework (e.g., Antel 1992, O'Neill and Sweetman 1998) or apply a two-stage least squares approach (2SLS) (e.g., Macmillan 2010). The 2SLS approach requires that at least one instrumental variable which strongly affects father's unemployment risk is exogenous (conditional on covariates) in equation (1). Although the bivariate probit can identify $\beta$ without exclusion restrictions, corresponding estimates are typically not robust to slight changes in specification. Hence, also for the bivariate probit at least one exclusion restriction is recommended. 
Finally, based on Gottschalk (1996) we add future parental unemployment to equation (1) yielding:

$$
u n_{s i t 1}=u n_{f i t 0} \beta+u n_{f i t 2} \theta+x_{s i t 1}^{\prime} \gamma+\varepsilon_{s i t 1}
$$

The idea behind the inclusion of future paternal unemployment in period $t 2$ (e.g. when the son is aged 25-30) is that it should have no causal impact on a son's unemployment if it occurs after the son is old enough to be unaffected by the father's labor market outcomes. If this is true, the parameter associated with future paternal unemployment $\left(u n_{f i t 2}\right)$ captures family background only. Subtracting it from the coefficient on prior paternal unemployment $\left(u n_{f i t 0}\right)$ estimates the causal effect of interest if an effect of son's unemployment on father's unemployment is ruled out. The obvious advantage of Gottschalk's (1996) method is that there is no need to find exclusion restrictions. ${ }^{3}$

\subsection{Empirical approach}

As the Gottschalk (1996) method and the methods relying on exclusion restrictions have different advantages and shortcomings, we will apply both types of models and compare the results. We start by estimating equation (1) via OLS. To extract as much family background from the error term as possible, we also add information on the father to equation (1). Based on empirical results for other countries, we expect a positive sign for $\beta$. A negative $\beta$ is theoretically possible if, e.g., the experience of having an unemployed father motivates the son to avoid own future unemployment. A negative sign is, however, unlikely as the negative causal effect would have to overcompensate the expected positive effect of family background.

$3 \quad$ Ekhaugen (2009:101) points out that it has additionally to be assumed that parents becoming unemployed after their offspring reaches the critical age are not systematically different from parents becoming unemployed before (identifying $\beta$ ). The author discusses that the approach may underestimate the causal effect if parental unemployment in t2 is correlated with child outcomes for other than family background mechanisms, e.g., due to shared regional labor markets. 
Before turning to the causal methods, we point out that the vector of son's control variables $\left(x_{\text {sit } 1}^{\prime}\right)$ does not contain information on son's education, or industry. These variables are themselves likely to be affected by father's unemployment. Including them constitutes a case of over-controlling, i.e., of extracting explanatory power originally belonging to father's unemployment $\left(u n_{f i t 0}\right)$. Later, we will add son's characteristics in order to test whether our (positive) estimate of $\beta$ becomes smaller. If it does, education and occupational choice are transmission channels for the intergenerational correlation in unemployment.

Our 2SLS instrumental variables approach relies on the availability of an instrumental variable that is strongly correlated with parental unemployment $\left(u n_{f i t 0}\right)$ but unrelated to $\varepsilon_{\text {sit } 1}$. We opt for industry level labor market conditions in $t 0$ because these should be related to father's unemployment propensity. ${ }^{4}$ In particular, we generate indicators of the annual industryspecific risk of a transition to unemployment and of the annual industry-specific stock of unemployment. As exogeneity of instruments cannot be tested, we must assume that unemployment in the father's industry is uncorrelated with unobserved determinants of son's unemployment years later. The exogeneity assumption is violated, e.g., if family background characteristics systematically cause fathers to be in certain industries. This might pose a problem in regions with only a handful of employers but should be less of a challenge in metropolitan areas where the choice of an industry is less restricted. Also, the instruments are invalid if there is a direct partial effect of the paternal industry characteristics on youth employment outcomes which we observe 9-16 years later based on mechanisms other than family unobservables. We additionally implement Gottschalk's (1996) approach by adding father's unemployment experience in $t 2$, i.e. after the son exceeds age 24 to the OLS regression.

$4 \quad$ We will be more explicit about the exact time structure in section 3. 


\subsection{Interpretation of overall, causal, and family background effects}

The OLS estimate of $\beta$, i.e., the overall effect, measures whether sons of unemployed fathers are more or less likely to become unemployed themselves. It therefore adds to our understanding of the sources of intergenerational (economic) mobility in Germany, which has typically been analyzed with respect to wage or education outcomes (e.g., Schnitzlein 2014, Heineck and Riphahn 2009). A high positive value of $\beta$ indicates low overall mobility and vice versa. We will study the heterogeneity of the overall effect, as the relevance of a high $\beta$ for sons of high-risk fathers differs from that for sons in low-risk families.

However, the overall effect does not tell us much about the sources of the intergenerational transmission of unemployment and appropriate policy interventions. The interpretation of $\beta$ depends on whether it reflects the effect of family background or the effect of paternal unemployment per se. If $\beta$ reflects the effect of family background, the sons' unemployment perspectives cannot be shaped by policy interventions that reduce paternal unemployment such as active labor market policies. Effective policies would then have to reduce the influence of family background, e.g., by offering special training or educational programs to children of unemployed parents. Contrarily, if $\beta$ reflects a positive causal effect, reducing paternal unemployment reduces unemployment of the future generation. Then, the costs associated with today's unemployment extend beyond the direct financial and indirect social costs of paternal unemployment.

\section{Data}

\subsection{Sample}

Our analysis exploits data from the German Socio-Economic panel (SOEP), a longitudinal survey conducted annually since 1984 (Wagner et al. 2007). We use all available annual waves (1984-2012) and all samples. The advantage of the SOEP is the long observation period and 
the availability of detailed information on family background and labor force status. We use retrospective biographical as well as annually collected survey information.

Compared to administrative data the SOEP comprises relatively small samples. At the same time the SOEP overcomes an important drawback of administrative data: it covers all unemployed persons, independent of whether they are officially registered. This allows a more flexible definition of unemployment which is particularly appropriate for the analysis of youth unemployment. Since youths are typically not eligible for unemployment benefits they tend not to register with the unemployment insurance.

We study youth unemployment among male respondents aged 17 to $24 .^{5}$ We drop observations with missing information on own labor force status ( $0.1 \%$ of the sample) and without information on fathers (28\% of the sample). To evaluate the impact of past paternal unemployment we collect information on fathers' unemployment for their sons' age range 10 to 15 using the annual self-reported employment status at the time of the interview. We drop observations of sons for whom we do not observe the father at least once in this age range. For our IV strategy we need to observe the father when the son was 8 years old and we require information on the last industry of fathers' employment, at least once. ${ }^{6}$ In the end, these sample selection criteria leave us with a sample of 2,175 sons. This is our primary sample for OLS and IV estimations. Table 1 shows our sample selection procedure in detail. For the application of the Gottschalk (1996) method we additionally need to observe fathers after their sons turn 25. For these analyses our sample size declines further to 1,266 observations. ${ }^{7}$

Since the additional information that can be gained from a panel structure is limited, we use only cross-sectional information; the key explanatory variable - father's years of unemployment at son's age 10 to 15 - does not vary over time. Consequently, considering panel

\footnotetext{
$5 \quad$ Female respondents would also be of interest. The intergenerational transmission of unemployment may differ for males and females. We leave the analysis of these differences for future work.

$6 \quad$ Deleting persons from our basic sample who never reported an industry is potentially endogenous. However, given that we lose only 37 persons this has minor consequences for our estimates.

$7 \quad$ For this subsample we omit the selection on observing the father when the son was 8 years old.
} 
data would shift weights in favor of individuals who are observed more often in the considered age range (17-24). As non-response and panel attrition at this age are potentially selective, we use each person only once in the estimation sample to limit the influence of confounding factors. We will exploit the panel structure of the data as a robustness check.

\subsection{Key variables}

Our dependent variable comprises the number of years during which the son has been registered unemployed or has been non-working between age 17 and 24, i.e. the classic age range considered in the definitions of youth unemployment. The main explanatory variable is father's registered unemployment in years at the son's age 10 to 15, i.e. in late childhood as collected from surveys of the fathers. We use sons' years of worklessness and fathers' years of registered unemployment, i.e., a broad definition of unemployment for the son and a more narrow definition for the father. ${ }^{8}$ In both cases we do not regard individuals as workless or unemployed if they are in full- or part-time employment, vocational training, tertiary education, or military and substitute service. Due to missing information we do not observe all fathers and sons in all years. Therefore, we control in our model for the number of years without information on labor market participation, both for the son and the father to avoid confounding effects of selective panel attrition. ${ }^{9}$

As discussed above our instrumental variable describes the industry-specific unemployment risk. This is based on the assumption that while paternal unemployment may be endogenous to sons' unemployment this endogeneity does not exist between the paternal choice of an industry when the son is a child and sons' unemployment outcomes as a young adult. To the extent that paternal choice of industry directly affects sons' youth unemployment our

\footnotetext{
8 About one third of the unemployed sons indicate worklessness whereas two thirds report to be registered unemployed.

$9 \quad$ About $35 \%$ of the sons in our final sample are observed for 8 or 9 subsequent years, $65 \%$ are available 3 to 7 years in sequence, and $20 \%$ are only observed once or twice. $55 \%$ of fathers are observed for the full period, $26 \%$ are observed 3 to 5 times, and 19\% are only observed once or twice.
} 
instrument is invalid. The measure is calculated on an annual basis and measures for each father the unemployment risk in his industry of employment when his son was 8 years old. ${ }^{10}$ This is used to instrument the father's unemployment when his son is aged 10 to 15 . More specifically, we code by industry the share of the number of employed workers in t-1 who enter unemployment in t relative to the sum of those employed in the specific industry in t plus those who entered unemployment (one year unemployment risk). As second measure of industryspecific unemployment risk we consider not entry to unemployment, a flow measure, but an indicator of the stock of unemployment (five year unemployment risk). We consider the number of prior industry employees who have been unemployed for between one and five years relative to the sum of employed workers in that industry in year t plus those unemployed. Both measures are calculated based on a two-digit industry code.

Table 2 describes the key variables by paternal unemployment status (one or more years unemployed when son was 10-15 years old vs. employed). ${ }^{11}$ The first row shows that sons' unemployment exposure is substantially longer if the father was unemployed at least once: while in total sons are unemployed for about 0.32 years in the age range 17 to 24 this figure amounts to 0.29 years for sons of fathers without past unemployment and almost double that period, i.e., 0.54 years for sons of fathers with past unemployment. Also, sons with an unemployed father tend to have lower educational attainment, a higher number of older siblings, and more often a migration background (first or second generation). As expected, we observe higher education among fathers who did not experience unemployment. ${ }^{12}$

\footnotetext{
10 In cases where fathers' industry was unobservable for this period we used information for earlier (or if those were not available either, for later) periods. If fathers' industry was never observed the observation was dropped.

11 To avoid selective sample reductions due to item non response in control variables we consider missing value categories in the specification.

12 We consider the highest educational attainment observed over the age years 17-24 for each youth.
} 


\section{4. $\quad$ Results}

We present our results in four steps: we start with the least squares perspective which combines any causal and family background effects in the coefficients of paternal unemployment background. In step two we apply estimators that intend to strip off any endogeneity from the paternal unemployment indicator either by means of instrumental variables estimation or by use of the Gottschalk (1996) approach. Once we understand the causal character of the observed correlation patterns, it is of interest to study heterogeneities and transmission channels in greater detail in step three and to undertake robustness tests as step four of our analysis.

\subsection{Conditional correlation patterns}

The first two columns of Table 3 present the coefficient estimate that results when we regress the number of years of sons' worklessness between ages 17 and 24 on the number of years fathers were unemployment when their sons were aged 10 to 15 . Column 1 describes the raw correlation, column 2 accounts for a set of family characteristics (i.e., year of birth of father and son, paternal education and migration background, sons' state of residence at age 10, sons' birth order, number of siblings, and the number of years with missing information on son and father). ${ }^{13}$

The unconditional correlation amounts to 0.103 and is highly statistical significant. Overall, the intergenerational unemployment correlation is thus positive and one additional year of paternal unemployment is associated with five additional weeks of sons' worklessness between ages 17 and 24. Given a mean duration of sons' worklessness of 16.5 weeks the relevance of paternal unemployment is limited. Once additional controls are considered the correlation drops by about half. While the estimate is still significantly different from zero the magnitude of the conditional correlation is small also by international comparison; O'Neill and

13 For the full specification and results of the linear regressions please see the Appendix. 
Sweetman (1998) find that sons' unemployment experience between ages 21 and 31 increases by about three months if their father experienced any unemployment when the son was aged 11 or 16. Ekhaugen (2009) shows that youths with at least one unemployed parent as a teenager had an unemployment propensity that was 57 to 95 percent higher than that of their peers without unemployed parents. Just as in our case, Ekhaugen (2009) finds that accounting for observed family heterogeneity reduces the gross intergenerational correlation in unemployment by half. Next, we investigate the evidence with respect to causal effects.

\subsection{Causality of conditional correlation patterns}

We apply two methods to inspect the evidence in favor of causal effects, instrumental variables and the Gottschalk (1996) method. Table 3 shows the estimation results for the IV approach (see columns 3-6). The first stage results for the one-year unemployment risk (i.e., unemployment entry) in columns 3 and 4 yield a significant positive correlation of aggregate unemployment risks with paternal unemployment. The five year unemployment measures are also positively associated with fathers' unemployment experience but the coefficients are estimated much less precisely. The first stage F-statistic reaches a value above 5 only in column 3 when no control variables are considered. Overall, our instruments are rather weak and the evidence has to be interpreted with caution.

The IV estimate of the effect of fathers' on sons' unemployment is negative in all four columns. Therefore, it provides no evidence in favor of a positive causal intergenerational transmission of unemployment. This suggests that the positive OLS coefficients exclusively reflect the effects of family background and of correlated observable or unobservable characteristics between fathers and sons but no causal effects. These findings match prior findings in the international literature. As an example, Macmillan (2010) instrumented paternal unemployment with being associated with a hard hit industry; the author finds an insignificant estimate of the causal paternal unemployment effect. 
Our second strategy to separate the true causal paternal unemployment effect from general family background correlation patterns follows Gottschalk (1996). Table 4 shows our estimation results. Because the Gottschalk specifications are estimated only on the subsample of observations for which we have evidence on paternal unemployment after the son reaches age 25, we re-estimated the OLS models on this subsample. The results in columns 1 and 2 confirm prior findings in Panel A, which uses 1,266 observations of sons for which the father was observed at least once both in the period when the son was aged 10-15 and when the son was aged 25-30. Once we require at least three observations on paternal employment outcomes during the sons' childhood and after age 25 the sample size drops to 719 (see Panel B). In Panel B we no longer obtain significant positive correlations between father and son unemployment in the least squares estimations. Thus, the results in Panel A may be more informative.

We show the estimation results of the Gottschalk (1996) approach in columns 3 and 4 without and with control variables. The estimated coefficient differences are never significant and in three out of four cases they are negative. ${ }^{14}$ Thus, after accounting for the family background effect no positive causal effect remains. This evidence confirms the IV results and suggests - in agreement with the international literature (e.g., Macmillan 2010, Ekhaugen 2009) - that there is no positive significant causal effect of father on son unemployment.

\subsection{Heterogenities and transmission channels}

Next we study potential heterogeneities in the observed correlation patterns. Table 5 presents the coefficients of least squares regressions that condition on similar sets of control variables as before. The results suggest that the intergenerational unemployment correlation is larger in West than in East Germany (see column 1). One possible explanation for this difference is the

\footnotetext{
14 In a robustness test we redid all estimations based on the Gottschalk approach when using paternal unemployment as measured at sons' age 10-13. The results of no significant positive causal effect are confirmed and the estimates of the difference in parameters are rather similar to those in Table 4.
} 
generally higher unemployment incidence in East Germany which renders unemployed families (and their unobserved characteristics) more similar to the average. In columns 2 and 3 we compare correlation patterns for natives and immigrants. Due to the small number of immigrants in East Germany the results cannot be presented for this subsample. Overall, the results suggest that intergenerational correlations are tighter in the native population. This confirms prior evidence on higher educational mobility among immigrants than natives (Bauer and Riphahn 2007).

In our sample of fathers the gradient of unemployment by postsecondary training is steep, with an average of 0.73 years of measured unemployment among fathers with low, 0.29 among fathers with medium, and 0.07 among fathers with high levels of education for the period when their sons were aged 10-15 (figures not presented). So clearly, a high intergenerational unemployment correlation would generate the worst outcome for sons of low educated fathers and would be beneficial in the case of highly educated fathers. Interestingly, the estimated correlation patterns in columns 4-6 of Table 5 yield that the intergenerational correlation of unemployment is high and statistically significant only in the medium education category. Therefore, neither do the sons of low educated fathers suffer nor do the sons of highly educated fathers benefit in any particular way. Instead the overall intergenerational correlation of unemployment outcomes is borne by the largest population group of medium educated fathers, which in our sample account for 52 percent of all fathers.

In Table 6 we present estimation results that describe the transmission channels between paternal and youth unemployment. In Panel A we commence by presenting the raw correlation between the two unemployment measures conditional on only a few covariates such as region, son's year of birth, and number of missing observations. We then add covariate groups based on their relevance for the considered correlation patterns: we start with paternal characteristics, then enter family characteristics and finally allow for youth characteristics that may be confounded by paternal unemployment. Already considering paternal year of birth and 
education (in column 2) reduces the correlation coefficient by one third. The family characteristics in column 3, i.e., migration background, birth order, and number of siblings does not add much to the explanation of the correlation patterns. In fact, Panel B shows that by themselves even the most basic paternal characteristics are more relevant to the unemployment correlation than the family indicators: compared to column 1 the coefficient declines more in column 2 than in column 3. When we consider additional characteristics of the son such as education and industry of employment the correlation coefficient declines further and loses statistical significance (see Panel A). ${ }^{15}$ Overall, all considered groups of covariates yield jointly statistically significant coefficient estimates and are correlated with sons' and fathers' unemployment outcomes; however, paternal characteristics are the most influential transmission mechanism.

\subsection{Robustness checks}

We submit our key results, i.e., a significant positive overall correlation between paternal and child unemployment but no positive causal effect to three robustness checks. First, we use the available panel data for sons' dichotomous annual worklessness outcomes between ages 17 and 24 instead of an aggregate count of the total number of years that we studied so far. Panel A of Table 7 shows the results of applying least squares and instrumental variables estimators to the now much larger sample of 10,893 observations. Here, we use 2,175 different observations on sons with about five annual observations on average and a mean annual unemployment probability of 0.06 percent. The estimation outcomes confirm prior results: the parent-child unemployment correlations in columns 1 and 2 are significantly positive, and the instrumental variables estimates yield insignificant negative coefficients, again based on potentially weak instruments.

\footnotetext{
15 This agrees well with the finding of Pinger (2012) who shows that parental unemployment significantly affects youth educational outcomes.
} 
Next, we return to the cross-sectional sample but replace the continuous unemployment measures for sons and fathers by dichotomous measures that describe whether son or father ever experienced at least one spell of unemployment in the respective considered periods, i.e., for sons at age 17-24 and for fathers at the time when their sons were aged 10-15. This shifts the focus to the extensive margin of the unemployment experience. Panel B of Table 7 shows the estimation results, which confirm prior findings: in columns 1 and 2 we obtain significant positive estimates, while the IV results yield negative insignificant unemployment coefficients throughout. The robustness test corroborates prior results.

In our final robustness test we investigate the sensitivity of the results to the definition of the period in which paternal unemployment is measured. Instead of focusing on fathers' unemployment when the son is aged 10-15 we now investigate the outcomes when using paternal unemployment in the sons' age range 10-13 only. This causes a slight decline in the number of observations, however, the overall outcome as shown in Panel C of Table 7 is robust: again we find positive correlations in the least squares results, but no evidence for a positive causal effect in the instrumental variables estimation (nor in the Gottschalk (1996) approach, which we do not present save space). Thus, our estimations are robust to three different robustness tests.

\section{Conclusions}

Even though youth unemployment is the most pressing problem in many European labor markets we know very little about the mechanisms behind it. While some authors address the role of demand and supply for young workers and the patterns of incidence and duration of youth unemployment we address one factor that so far has been neglected in many discussions and certainly in the literature on German youth unemployment: the impact of family background. This paper studies the intergenerational correlation between the unemployment 
experiences of fathers and their sons. The international literature features only few contributions on the subject.

Several mechanisms may generate a correlation between the employment outcomes of fathers and their sons; we can think of observable characteristics that run in the family and of unobservable traits and attitudes that may be transmitted from parent to child. In addition, it is of particular interest to determine whether there is a causal effect that makes sons more (or less) likely to experience unemployment once they have seen their fathers unemployed. A variety of reasons may be behind such causal mechanisms and their relevance is obvious: if there is a causal intergenerational transmission of unemployment this provides an additional rationale for labor market policy supporting the employment opportunities of parents. If no such causal connection can be established the fight against youth unemployment may be more successful if it focuses on youths themselves.

This paper shows that the unemployment experience of German fathers and sons is positively correlated. We apply standard empirical approaches to test whether the character of these correlations is causal. Our results are robust to the application of instrumental variables techniques, the application of Gottschalk's (1996) method, to considering outcomes at the intensive and the extensive margin, and to applying data in a cross-sectional and panel data setting: while parent and child unemployment experiences are significantly positively correlated, this correlation does not go back to a causal effect. Instead, family background affects the unemployment risks of both fathers and their sons. Our results agree with most of the literature on intergenerational unemployment transmission, which confirms positive correlations but rejects causal mechanisms. 


\section{References}

Antel, J.J. (1992), The intergenerational transfer of welfare dependency: Some statistical evidence. The Review of Economics and Statistics, 74: 467-473.

Bauer, P.C., R.T. Riphahn (2007), Heterogeneity in the Intergenerational Transmission of Educational Attainment: Evidence from Switzerland on Natives and Second Generation Immigrants. Journal of Population Economics 20: 121-148.

Beaulieu, N., J.-Y. Duclos, B. Fortin, M. Rouleau (2005), Intergenerational reliance on social assistance: Evidence from Canada. Journal of Population Economics 18: 539-562.

Blomeyer, D., M. Laucht, K. Coneus, F. Pfeiffer (2013), Early Life Adversity and Children's Competence Development: Evidence from the Mannheim Study of Children at Risk. Jahrbücher für Nationalökonomie und Statistik (Journal of Economics and Statistics) 233: 467-485.

Bratberg, E., O. Anti Nilsen, K. Vaage (2008), Job losses and child outcomes. Labour Economics 15: 591-603.

Corak, M., B. Gustafsson, T. Österberg (2004), Intergenerational influences on the receipt of unemployment insurance in Canada and Sweden. Pp. 245-288, in: M. Corak (ed.), Generational income mobility in North America and Europe, Cambridge University Press, Cambridge.

Couch, K.A., Dunn T.A. (1997), Intergenerational Correlations in Labor Market States. A Comparison of the United States and Germany, Journal of Human Resources 32: 210232.

De Paola, M. (2013), The determinants of Risk Aversion: The Role of Intergenerational Transmission. German Economic Review 14: 214-234.

Edmark, K., K. Hanspers (2012), Is welfare dependency inherited? Estimating the causal welfare transmission effects using Swedish sibling data. IFN working paper No. 894, Stockholm.

Ekhaugen, T. (2009), Extracting the causal component from the intergenerational correlation in unemployment. Journal of Population Economics 22: 97-113.

Franz, W., J. Inkmann, W. Pohlmeier, V. Zimmermann (2000). Young and Out in Germany. On Youths' Chances of Labor Market Entrance in Germany. In: D. Blanchflower, R. Freeman (Eds.), Youth Unemployment and Joblessness in Advanced Countries. NBER Cambridge, MA, 381-426.

Gottschalk, P. (1990), AFDC participation across generations. American Economic Review 80: 367-371.

Gottschalk, P. (1996), Is the correlation in welfare participation across generations spurious?. Journal of Public Economics 63: 1-25.

Gregg, P. (2001), The impact of youth unemployment on adult unemployment in the NCDS. Economic Journal 111: F626-F653.

Gregg, P., L. Macmillan, B. Nasim (2012), The impact of fathers' job loss during the recession of the 1980s on their children's educational attainment and labour market outcomes. Fiscal Studies 33: 237-264.

Heineck, G., R.T. Riphahn (2009), Intergenerational Transmission of Educational Attainment in Germany - The Last Five Decades. Journal of Economics and Statistics (Jahrbücher für Nationalökonomie und Statistik) 229: 36-60.

Johnson, P., H. Reed (1996), Intergenerational mobility among the rich and poor: results from the National Child Development Survey. Oxford Review of Economic Policy 12: 12742.

Macmillan, L. (2010), The Intergenerational Transmission of Worklessness in the UK. CMPO Working Paper Series No. 10/231. Bristol. 
O'Neill, D., O. Sweetman (1998), Intergenerational mobility in Britain: evidence from unemployment patterns. Oxford Bulletin of Economics and Statistics 60: 431-447.

Oreopoulos, P., M. Page, A. Huff Stevens (2008), The intergenerational effect of worker displacement. Journal of Labor Economics 26: 455-483.

Pinger, P.R. (2012), Intergenerational Effects of Economic Distress: Paternal Unemployment and Child Secondary Schooling Decisions. mimeo. University of Mannheim.

Riphahn, R.T., M. Zibrowius (2014), Apprenticeship, Vocational Training and Early Labor Market Outcomes - Evidence from East and West Germany, mimeo, University of Erlangen-Nuremberg.

Schmillen, A., M. Umkehrer (2013), The scars of youth. Effects of early-career unemployment on future unemployment experience, IAB Discussion Paper No. 6/2013, Nürnberg.

Schnitzlein, D. D. (2014), How important is the family? Evidence from sibling correlations in permanent earnings in the USA, Germany, and Denmark. Journal of Population Economics 27: 69-89.

Wagner, G.G., J.R. Frick, J. Schupp (2007), The German Socio-Economic Panel Study (SOEP) - Scope, Evolution and Enhancements. Schmollers Jahrbuch (Journal of Applied Social Science Studies) 127: 139-169. 
Table 1: $\quad$ Sample selection

\begin{tabular}{rrr}
\hline & Persons & Person-Years \\
\hline Male respondents aged 17-24 & 7,614 & 31,339 \\
- $\quad$ Missing labor force status & 8 & 20 \\
- $\quad$ Father not observed or no biographical questionnaire & 2,156 & 5,329 \\
$\quad$ answered & & \\
- $\quad$ Father not observed at son's age 10-15 & 2,412 & 9,734 \\
- $\quad$ Father not observed at son's age 8 & 759 & 4,750 \\
$-\quad$ Missing father's industry & 104 & 613 \\
\hline$=$ & 2,175 & 10,893 \\
\hline
\end{tabular}

Note: "-" stands for minus; the number of cases in the first row describes the magnitude of the initial raw sample. Each row provides the number of observations lost for the row-specific selection criterion. The numbers depend on the order of applied criterions. The last row provides the sample sizes available for the analysis.

Source: SOEP 1984-2012, own calculations. 
Table 2: $\quad$ Descriptive statistics

\begin{tabular}{|c|c|c|c|}
\hline & $\begin{array}{l}\text { Father never } \\
\text { unemployed }\end{array}$ & $\begin{array}{r}\text { Years father } \\
\text { unemployed }>0\end{array}$ & Full Sample \\
\hline \multirow[t]{2}{*}{ Number of years son workless } & 0.286 & 0.538 & 0.318 \\
\hline & $(0.719)$ & $(0.988)$ & $(0.763)$ \\
\hline \multirow[t]{2}{*}{ Years father unemployed while son aged 10-15 } & 0 & 2.047 & 0.263 \\
\hline & $(0.000)$ & $(1.306)$ & $(0.829)$ \\
\hline \multirow[t]{2}{*}{ Number of years son not observed age $17-24$} & 2.996 & 2.964 & 2.992 \\
\hline & $(2.523)$ & $(2.437)$ & $(2.511)$ \\
\hline \multirow[t]{2}{*}{ Number of years father not observed (son aged 10-15) } & 0.951 & 0.588 & 0.904 \\
\hline & $(1.569)$ & $(1.199)$ & $(1.531)$ \\
\hline \multicolumn{4}{|l|}{ Sons' characteristics } \\
\hline \multirow[t]{2}{*}{ Sons' year of birth } & 1986.139 & 1985.695 & 1986.082 \\
\hline & $(5.047)$ & (4.789) & $(5.016)$ \\
\hline \multirow[t]{2}{*}{ Lower secondary school degree (Hauptschulabschluss) } & 0.170 & 0.240 & 0.179 \\
\hline & $(0.376)$ & $(0.428)$ & $(0.383)$ \\
\hline \multirow[t]{2}{*}{ Intermediate school degree (Mittlere Reife) } & 0.259 & 0.280 & 0.262 \\
\hline & $(0.438)$ & $(0.450)$ & $(0.440)$ \\
\hline \multirow[t]{2}{*}{$\begin{array}{l}\text { Upper secondary school degree (Abitur)/Technical school } \\
\text { dregree (Fachhochschulreife) }\end{array}$} & 0.253 & 0.115 & 0.235 \\
\hline & $(0.435)$ & $(0.319)$ & $(0.424)$ \\
\hline \multirow[t]{2}{*}{ Other degree/No school degree/Missing information } & 0.022 & 0.050 & 0.026 \\
\hline & $(0.147)$ & $(0.219)$ & $(0.158)$ \\
\hline \multirow[t]{2}{*}{ Currently in school } & 0.296 & 0.315 & 0.299 \\
\hline & $(0.457)$ & $(0.466)$ & $(0.458)$ \\
\hline \multirow[t]{2}{*}{ Sons' number of siblings } & 1.642 & 2.036 & 1.692 \\
\hline & $(1.335)$ & $(1.385)$ & $(1.348)$ \\
\hline \multirow[t]{2}{*}{ Sons' birthorder } & 1.830 & 2.140 & 1.869 \\
\hline & $(0.949)$ & $(1.184)$ & $(0.988)$ \\
\hline \multicolumn{4}{|l|}{ Migration background } \\
\hline \multirow[t]{2}{*}{ No migration background } & 0.806 & 0.642 & 0.785 \\
\hline & $(0.395)$ & $(0.480)$ & $(0.411)$ \\
\hline \multirow[t]{2}{*}{ Direct migration background } & 0.180 & 0.344 & 0.201 \\
\hline & $(0.384)$ & $(0.476)$ & $(0.401)$ \\
\hline \multirow[t]{2}{*}{ Indirect migration background } & 0.014 & 0.014 & 0.014 \\
\hline & $(0.116)$ & $(0.119)$ & $(0.117)$ \\
\hline \multicolumn{4}{|l|}{ Fathers' Characteristics } \\
\hline \multirow[t]{2}{*}{ Fathers' year of birth } & 1956.109 & 1956.140 & 1956.113 \\
\hline & $(6.895)$ & $(8.274)$ & $(7.085)$ \\
\hline \multirow[t]{2}{*}{ Father lived in East Germany at sons' age 10} & 0.267 & 0.409 & 0.286 \\
\hline & $(0.443)$ & $(0.492)$ & $(0.452)$ \\
\hline \multicolumn{4}{|l|}{ Secondary Schooling } \\
\hline \multirow[t]{2}{*}{ Lower secondary school degree (Hauptschulabschluss) } & 0.313 & 0.330 & 0.315 \\
\hline & $(0.464)$ & $(0.471)$ & $(0.465)$ \\
\hline \multirow[t]{2}{*}{ Intermediate school degree (Mittlere Reife) } & 0.322 & 0.308 & 0.320 \\
\hline & $(0.467)$ & $(0.463)$ & $(0.467)$ \\
\hline Technical school degree (Fachhochschulreife) & 0.050 & 0.004 & 0.044 \\
\hline
\end{tabular}




\begin{tabular}{lrrr} 
& $(0.218)$ & $(0.060)$ & $(0.205)$ \\
Upper secondary school degree (Abitur) & 0.205 & 0.068 & 0.187 \\
& $(0.404)$ & $(0.252)$ & $(0.390)$ \\
Other degree & 0.080 & 0.176 & 0.092 \\
& $(0.271)$ & $(0.381)$ & $(0.289)$ \\
No school degree & 0.031 & 0.115 & 0.041 \\
& $(0.172)$ & $(0.319)$ & $(0.199)$ \\
Postsecondary education & & & \\
No postsecondary education & 0.084 & 0.226 & 0.103 \\
& $(0.278)$ & $(0.419)$ & $(0.303)$ \\
Other vocational training & 0.116 & 0.208 & 0.127 \\
& $(0.320)$ & $(0.407)$ & $(0.333)$ \\
Industrial/commercial/health care apprenticeship & 0.415 & 0.441 & 0.418 \\
Technical college, civil servant training & $(0.493)$ & $(0.497)$ & $(0.493)$ \\
& 0.133 & 0.047 & 0.122 \\
University degree & $(0.340)$ & $(0.211)$ & $(0.327)$ \\
& 0.249 & 0.075 & 0.227 \\
Missing information & $(0.433)$ & $(0.264)$ & $(0.419)$ \\
& 0.004 & 0.004 & 0.004 \\
\hline Number of observations & $(0.061)$ & $(0.060)$ & $(0.061)$ \\
\hline
\end{tabular}

Note: Table shows means and standard deviations in parentheses of key variables.

Source: SOEP 1984-2012, own calculations. 
Table 3: $\quad$ Estimation results using OLS and IV methods

\begin{tabular}{|c|c|c|c|c|c|c|}
\hline & \multicolumn{2}{|c|}{ OLS } & \multicolumn{4}{|c|}{ IV-Results } \\
\hline & \multirow{3}{*}{$\begin{array}{r}\text { Without } \\
\text { controls } \\
(1) \\
\end{array}$} & \multirow{3}{*}{$\begin{array}{r}\text { With } \\
\text { controls } \\
(2)\end{array}$} & \multicolumn{2}{|c|}{1 year unemployment risk } & \multicolumn{2}{|c|}{5 year unemployment risk } \\
\hline & & & $\begin{array}{l}\text { Without } \\
\text { controls }\end{array}$ & $\begin{array}{l}\text { With } \\
\text { controls }\end{array}$ & $\begin{array}{l}\text { Without } \\
\text { controls }\end{array}$ & $\begin{array}{r}\text { With } \\
\text { controls }\end{array}$ \\
\hline & & & (3) & $(4)$ & $(5)$ & (6) \\
\hline \multirow[t]{2}{*}{ Years father unemployed } & $0.103 * * *$ & $0.053^{* *}$ & -0.020 & -0.126 & -0.106 & -0.225 \\
\hline & $(0.026)$ & $(0.026)$ & $(0.285)$ & $(0.400)$ & $(0.410)$ & $(0.595)$ \\
\hline \multicolumn{7}{|l|}{ First stage results } \\
\hline First stage F-statistic & - & - & 8.64 & 4.28 & 3.51 & 1.78 \\
\hline \multirow[t]{2}{*}{ First stage coefficient } & - & - & $1.470 * * *$ & $1.109 * *$ & $0.522 *$ & 0.433 \\
\hline & & & $(0.500)$ & $(0.536)$ & $(0.278)$ & $(0.325)$ \\
\hline Number of observations & 2175 & 2175 & 2175 & 2175 & 2175 & 2175 \\
\hline Number of controls & 1 & 51 & 1 & 51 & 1 & 51 \\
\hline
\end{tabular}

Note: Columns (3)-(6) show IV-results with two instruments of unemployment risk. Each coefficient represents a separate linear regression. Dependent variable is years a son experienced worklessness between ages 17 and 24. Standard errors in parentheses are clustered at fathers' person number, control variables are dummies for year of birth (son and father), fathers' education, fathers' migration background, sons' state of residence at age 10, sons' birth order, sons' number of siblings, number of years son is not observed (age 17-24), number of years father is not observed (sons age 10-15).

Source: SOEP 1984-2012, own calculations. 
Table 4: $\quad$ Estimation results using the Gottschalk method

\begin{tabular}{|c|c|c|c|c|}
\hline & $\begin{array}{c}\text { (1) } \\
\text { OLS } \\
\text { no controls } \\
\end{array}$ & $\begin{array}{c}\text { (2) } \\
\text { OLS } \\
\text { with controls }\end{array}$ & $\begin{array}{c}\text { (3) } \\
\text { Gottschalk } \\
\text { no controls }\end{array}$ & $\begin{array}{c}(4) \\
\text { Gottschalk } \\
\text { with controls }\end{array}$ \\
\hline \multicolumn{5}{|c|}{ Panel A: Father observed at least once } \\
\hline $\begin{array}{l}\text { Years father unemployed } \\
\text { while son aged } 10-15\end{array}$ & $\begin{array}{l}0.152^{* *} \\
(0.060)\end{array}$ & $\begin{array}{c}0.046 \\
(0.065)\end{array}$ & $\begin{array}{c}0.123^{* *} \\
(0.061)\end{array}$ & $\begin{array}{c}0.046 \\
(0.065)\end{array}$ \\
\hline $\begin{array}{l}\text { Years father unemployed } \\
\text { while son aged } 25-30\end{array}$ & - & - & $\begin{array}{c}0.101^{* * *} \\
(0.027)\end{array}$ & $\begin{array}{l}0.052^{*} \\
(0.029)\end{array}$ \\
\hline Difference & - & - & $\begin{array}{c}0.022 \\
(0.069)\end{array}$ & $\begin{array}{l}-0.006 \\
(0.074)\end{array}$ \\
\hline Number of observations & 1266 & 1266 & 1266 & 1266 \\
\hline Number of controls & 1 & 47 & 2 & 48 \\
\hline \multicolumn{5}{|c|}{ Panel B: Father observed at least 3 times } \\
\hline $\begin{array}{l}\text { Years father unemployed } \\
\text { while son aged } 10-15\end{array}$ & $\begin{array}{c}0.091 \\
(0.072)\end{array}$ & $\begin{array}{l}-0.046 \\
(0.080)\end{array}$ & $\begin{array}{c}0.049 \\
(0.073)\end{array}$ & $\begin{array}{l}-0.045 \\
(0.080)\end{array}$ \\
\hline $\begin{array}{l}\text { Years father unemployed } \\
\text { while son aged 25-30 }\end{array}$ & - & - & $\begin{array}{c}0.116^{* * * *} \\
(0.031)\end{array}$ & $\begin{array}{l}0.054^{*} \\
(0.032) \\
\end{array}$ \\
\hline Difference & - & - & $\begin{array}{l}-0.067 \\
(0.083)\end{array}$ & $\begin{array}{l}-0.099 \\
(0.092)\end{array}$ \\
\hline Number of observations & 719 & 719 & 719 & 719 \\
\hline Number of controls & 1 & 45 & 2 & 46 \\
\hline
\end{tabular}

Note: Each column represents a separate linear regression. Dependent variable is years son experienced worklessness between ages 17 and 24. In the sample we use in Panel A fathers who are observed at least one year both in the before (son age 10-15) and the after period (son age 25-30), whereas in Panel B the fathers are observed at least three times respectively. Columns (1) and (2) show OLS-results for the respective samples, columns (3) and (4) present results by using the Gottschalk-method. Columns (1) and (3) exclude and columns (2) and (4) include control variables. Standard errors in parentheses are clustered at fathers' person number, control variables are indicators for year of birth (son and father), fathers' education, fathers' migration background, sons' state of residence at age 10, sons' birth order, sons' number of siblings, number of years son is not observed (age 17-24), number of years father is not observed (sons age 10-15 and age 25-30).

Source: SOEP 1984-2012, own calculations. 
Table 5: Heterogeneities in linear regression results

\begin{tabular}{|c|c|c|c|c|c|c|}
\hline & \multirow[t]{2}{*}{ All } & \multicolumn{2}{|c|}{$\begin{array}{c}\text { Fathers' migration } \\
\text { background }\end{array}$} & \multicolumn{3}{|c|}{ Fathers' postsecondary education } \\
\hline & & no & yes & low & medium & high \\
\hline Panel A: West Germany & (1) & (2) & (3) & (4) & (5) & (6) \\
\hline \multirow[t]{2}{*}{ Years father unemployed } & $0.060 *$ & $0.111^{* *}$ & 0.025 & -0.036 & $0.148^{* *}$ & 0.007 \\
\hline & $(0.037)$ & $(0.051)$ & $(0.051)$ & $(0.058)$ & $(0.057)$ & $(0.074)$ \\
\hline Number of observations & 1554 & 1110 & 444 & 235 & 775 & 542 \\
\hline Number of controls & 36 & 33 & 33 & 31 & 32 & 32 \\
\hline \multicolumn{7}{|l|}{ Panel B: East Germany } \\
\hline \multirow[t]{2}{*}{ Years father unemployed } & 0.037 & 0.039 & - & - & 0.045 & 0.005 \\
\hline & $(0.037)$ & $(0.038)$ & - & - & $(0.044)$ & $(0.066)$ \\
\hline Number of observations & 621 & 598 & 23 & 39 & 360 & 216 \\
\hline Number of controls & 36 & 33 & - & - & 29 & 30 \\
\hline \multicolumn{7}{|l|}{ Panel C: Full sample } \\
\hline \multirow[t]{2}{*}{ Years father unemployed } & $0.053^{* *}$ & $0.082 * * *$ & 0.016 & 0.001 & $0.114^{* * *}$ & 0.017 \\
\hline & $(0.026)$ & $(0.030)$ & $(0.049)$ & $(0.047)$ & $(0.038)$ & $(0.047)$ \\
\hline \multirow[t]{2}{*}{ Number of observations } & 2175 & 1708 & 467 & 274 & 1135 & 758 \\
\hline & 51 & 34 & 33 & 32 & 32 & 32 \\
\hline
\end{tabular}

Note: Each coefficient represents a separate linear OLS regression. Dependent variable is years son experienced worklessness between ages 17 and 24. Standard errors in parentheses are clustered at fathers' person number, control variables are indicators for year of birth (son and father), fathers' education, fathers' migration background (not for subgroups by migration background), sons' birth order, sons' number of siblings, number of years son is not observed (age 17-24), number of years father is not observed (sons age 10-15). We only present results for subgroups with at least 100 observations. Fathers' postsecondary education is defined as follows, low: without tertiary degree or still in education; medium: apprenticeship training or in-firm training; high: master, technical college, university.

Source: SOEP 1984-2012, own calculations. 
Table 6: $\quad$ Linear regression results on transmission mechanisms

\begin{tabular}{lrrrr}
\hline Panel A: Inclusion jointly & $(1)$ & $(2)$ & $(3)$ & $(4)$ \\
\hline Years father unemployed & $0.105^{* * *}$ & $0.065^{* *}$ & $0.053^{* *}$ & 0.037 \\
& $(0.025)$ & $(0.026)$ & $(0.026)$ & $(0.026)$ \\
\hline Basic controls (26) & $\mathrm{F}=8.44$ & $\mathrm{~F}=6.58$ & $\mathrm{~F}=6.84$ & $\mathrm{~F}=6.23$ \\
Father characteristics (14) & - & $\mathrm{F}=6.15$ & $\mathrm{~F}=4.96$ & $\mathrm{~F}=3.03$ \\
Family characteristics (10) & - & - & $\mathrm{F}=2.49$ & $\mathrm{~F}=2.03$ \\
Son characteristics (46) & - & - & - & $\mathrm{F}=6.06$ \\
Number of observations & 2175 & 2175 & 2175 & 2175 \\
Number of controls & 27 & 41 & 51 & 97 \\
\hline Panel B: Inclusion pairwise & & & & \\
\hline Years father unemployed & $0.105^{* * *}$ & $0.065^{* *}$ & $0.073^{* * *}$ & $0.068^{* * *}$ \\
& $(0.025)$ & $(0.026)$ & $(0.026)$ & $(0.024)$ \\
\hline Basic controls (26) & $\mathrm{F}=8.44$ & $\mathrm{~F}=6.58$ & $\mathrm{~F}=7.92$ & $\mathrm{~F}=6.31$ \\
Father characteristics (14) & - & $\mathrm{F}=6.15$ & - & - \\
Family characteristics (10) & - & - & $\mathrm{F}=3.45$ & - \\
Son characteristics (46) & - & - & - & $\mathrm{F}=12.04$ \\
Number of observations & 2175 & 2175 & 2175 & 2175 \\
Number of controls & 27 & 41 & 37 & 73 \\
\hline
\end{tabular}

Note: Each coefficient represents a separate linear OLS regression. Dependent variable is years son experienced worklessness between ages 17 and 24. Standard errors in parentheses are clustered at fathers' person number. The control variable groups are defined as follows: (a) basic controls: sons year of birth, number of years son (father) missing when son was 17-24 (10-15), state dummies; (b) fathers characteristics: year of birth dummies, education (secondary and tertiary); (c) family characteristics: migration background, number of siblings, birth order; (d) sons characteristics: industry (2 digit), education (highest completed).

Source: SOEP 1984-2012, own calculations. 


\begin{tabular}{rrrrrrr}
\multicolumn{2}{c}{ OLS } & & \multicolumn{4}{c}{ IV-Results } \\
\cline { 5 - 7 } \cline { 5 - 7 } Without & With & & \multicolumn{2}{c}{ 1 year unemployment risk } & 5 year unemployment risk \\
controls & controls & & controls & Controls & controls & controls \\
$(1)$ & $(2)$ & $(3)$ & $(4)$ & Without & $(6)$
\end{tabular}

Panel A: Panel structure - dependent var.: dichotomous indicator of annual son unemployment

\begin{tabular}{lrrrrrr} 
Years father unemployed & $\begin{array}{r}0.022^{* * *} \\
(0.005)\end{array}$ & $\begin{array}{r}0.012^{* *} \\
(0.005)\end{array}$ & $\begin{array}{r}-0.012 \\
(0.063)\end{array}$ & $\begin{array}{r}-0.022 \\
(0.088)\end{array}$ & $\begin{array}{r}-0.041 \\
(0.117)\end{array}$ & $\begin{array}{r}-0.067 \\
(0.209)\end{array}$ \\
\hline First stage results & & & & & & \\
First stage F-statistic & - & - & 7.57 & 3.30 & 1.44 & 0.57 \\
First stage coefficient & - & - & $1.310^{* * *}$ & $1.003^{*}$ & 0.368 & 0.267 \\
& & & $(0.476)$ & $(0.552)$ & $(0.307)$ & $(0.354)$ \\
\hline Number of observations & 10,893 & 10,893 & 10,893 & 10,893 & 10,893 & 10,893 \\
Number of controls & 1 & 51 & 1 & 51 & 1 & 51 \\
\hline
\end{tabular}

Panel B: Cross-section data - dependent var.: dichotomous indicator whether son ever unemployed

\begin{tabular}{lrrrrrr} 
Father ever unemployed & $0.040^{* * *}$ & $0.030^{*}$ & -0.147 & -0.212 & -0.093 & -0.305 \\
$(0 / 1)$ & $(0.015)$ & $(0.016)$ & $(0.133)$ & $(0.205)$ & $(0.264)$ & $(0.518)$ \\
\hline First stage results & & & & & & \\
First stage F-statistic & - & - & 11.06 & 5.54 & 2.69 & 1.01 \\
First stage coefficient & - & - & $0.740^{* * *}$ & $0.568^{* *}$ & 0.168 & 0.121 \\
& & & $(0.223)$ & $(0.242)$ & $(0.102)$ & $(0.120)$ \\
\hline Number of observations & 2175 & 2175 & 2175 & 2175 & 2175 & 2175 \\
Number of controls & 1 & 51 & 1 & 51 & 1 & 51 \\
\hline
\end{tabular}

Panel C: Cross-section data - measuring paternal unemployment at sons' age 10-13 only

\begin{tabular}{|c|c|c|c|c|c|c|}
\hline Years father unemployed & $\begin{array}{r}0.118^{* * * *} \\
(0.039)\end{array}$ & $\begin{array}{c}0.050 * \\
(0.038)\end{array}$ & $\begin{array}{r}-0.101 \\
(0.382)\end{array}$ & $\begin{array}{r}-0.159 \\
(0.475)\end{array}$ & $\begin{array}{r}-0.146 \\
(0.475)\end{array}$ & $\begin{array}{r}-0.193 \\
(0.660)\end{array}$ \\
\hline \multicolumn{7}{|l|}{ First stage results } \\
\hline First stage F-statistic & - & - & 8.87 & 5.71 & 4.63 & 2.37 \\
\hline First stage coefficient & - & - & $\begin{array}{r}1.146^{* * *} \\
(0.385) \\
\end{array}$ & $\begin{array}{r}0.961^{* *} \\
(0.402) \\
\end{array}$ & $\begin{array}{r}0.463 * * \\
(0.215) \\
\end{array}$ & $\begin{array}{r}0.380 \\
(0.246) \\
\end{array}$ \\
\hline Number of observations & 1960 & 1960 & 1960 & 1960 & 1960 & 1960 \\
\hline Number of controls & 1 & 51 & 1 & 51 & 1 & 51 \\
\hline
\end{tabular}

Note: Columns (3)-(6) show IV-results with two instruments of unemployment risk. Each coefficient represents a separate linear regression. Dependent variable is years son experienced worklessness between ages 17 and 24. Standard errors in parentheses clustered at fathers person number, control variables are dummies for year of birth (son and father), fathers' education, fathers' migration background, sons' state of residence at age 10, sons' birth order, sons' number of siblings, number of years son is not observed (age 17-24), number of years father is not observed while son aged 10-15 (and 10-13 in Panel C).

Source: SOEP 1984-2012, own calculations. 
Appendix: Full regression results

\begin{tabular}{|c|c|c|}
\hline & $(1)$ & (2) \\
\hline \multirow[t]{2}{*}{ Number of years father unemployed } & $0.103^{* * *}$ & $0.053^{*}$ \\
\hline & $(0.026)$ & $(0.026)$ \\
\hline \multirow[t]{2}{*}{ Number of years son not observed age 17-24 } & - & $-0.067 * * *$ \\
\hline & & $(0.007)$ \\
\hline \multirow[t]{2}{*}{ Number of years father not observed (son aged 10-15) } & - & 0.006 \\
\hline & & $(0.012)$ \\
\hline \multicolumn{3}{|l|}{ Sons' year of birth } \\
\hline \multirow[t]{2}{*}{$1977-1978$} & - & 0.001 \\
\hline & & $(0.086)$ \\
\hline \multirow[t]{2}{*}{ 1979-1980 } & - & -0.002 \\
\hline & & $(0.077)$ \\
\hline \multirow[t]{2}{*}{ 1981-1982 } & - & 0.140 \\
\hline & & $(0.078)$ \\
\hline \multirow[t]{2}{*}{ 1983-1984 } & - & 0.011 \\
\hline & & $(0.082)$ \\
\hline \multirow[t]{2}{*}{ 1985-1986 } & - & 0.093 \\
\hline & & $(0.071)$ \\
\hline \multirow[t]{2}{*}{ 1987-1988 } & - & -0.032 \\
\hline & & $(0.065)$ \\
\hline \multirow[t]{2}{*}{ 1989-1990 } & - & -0.043 \\
\hline & & $(0.058)$ \\
\hline \multirow[t]{2}{*}{ 1991-1992 } & - & -0.059 \\
\hline & & $(0.052)$ \\
\hline \multirow[t]{2}{*}{ 1993-1994 } & - & -0.052 \\
\hline & & $(0.044)$ \\
\hline 1995 & - & Reference \\
\hline
\end{tabular}

Fathers' year of birth

1929-1939

Reference

1940-1949

$-0.131$

(0.199)

1950-1959

$-0.123$

(0.192)

1960-1969

$-0.035$

(0.199)

1970-1975

$-0.196$

(0.206)

Fathers' secondary schooling

Lower secondary school degree

$-0.106$

(0.122)

Intermediate school degree

$-0.170$

(0.125)

Technical school degree

$-0.162$ 
\begin{tabular}{ll} 
Upper secondary school degree & - \\
\hline
\end{tabular}

Other degree

No School Degree

Reference

Fathers' postsecondary education

No postsecondary education

Reference

Vocational training

0.006

(0.086)

Industrial/commercial/health care apprenticeship

$-0.143^{*}$

(0.071)

Technical college, Civil servant training

$-0.263 * * *$

(0.072)

University

$-0.232 * *$

(0.072)

Missing

$-0.329 *$

(0.158)

Sons' number of siblings

No siblings

$-0.146^{* *}$

(0.148)

1 sibling

$-0.263^{* *}$

(0.090)

2 siblings

$-0.212 *$

(0.091)

3 siblings

$-0.215^{*}$

(0.102)

$>4$ siblings

Reference

\section{Sons' birth order}

1st born

$-0.133$

(0.134)

2nd born

$-0.055$

(0.138)

3rd born

$-0.103$

(0.141)

$>$ 4rd born

Reference

Missing

Fathers' migration background

No migration background

Reference

Direct migration background 
Note: Each column represents a separate linear regression. Dependent variable is years son experienced worklessness between ages 17 and 24. Standard errors in parentheses are clustered at fathers' person number.

Source: SOEP 1984-2012, own calculations. 